Allpanchis, año XLVIII, núm. 88. Arequipa, julio-diciembre de 2021, pp. 111-142.

ISSN impreso 0252-8835 / ISSN en línea 2708-8960

DOI: https://doi.org/10.36901/allpanchis.v48i88.1213

\title{
dossier
}

\section{El clero católico y la construcción nacional argentina (1862-1916)}

\author{
Roberto Di STEFANO \\ Universidad Nacional de La Pampa (La Pampa, Argentina) \\ distefanoster@gmail.com \\ Código ORCID: 0000-0002-9594-405X
}

RESUMEN

A diferencia del resto de los países latinoamericanos — con la sola excepción de Costa Rica-, la Argentina nunca separó jurídicamente la Iglesia y el Estado. Los gobiernos «liberales» del período conocido como «organización nacional» (1862-1880) y del llamado «orden conservador» (1880-1916), incluidos los que condujeron el país durante los ásperos debates públicos que acompañaron la sanción de las «leyes laicas» de la década de 1880, vieron en el cristianismo un elemento fundamental de la «civilización» y en la Iglesia católica una aliada necesaria para la construcción de la nación, del Estado y del «progreso». El artículo, sobre la base de fuentes ministeriales y parlamenta- 
rias, analiza los consensos y disensos en el modo en que la elite dirigente concibió la agencia del clero católico en el proceso de construcción nacional.

Palabras clave: Argentina, siglo XIX, nación, catolicismo, clero

\title{
The Catholic clergy and the Argentine national construction (1862- 1916)
}

\begin{abstract}
Unlike the rest of the Latin American countries — with the sole exception of Costa Rica- Argentina never legally separated the Church and the State. The «liberal» governments of the period known as the «national organization» (1862-1880) and of the so-called «conservative order» (1880-1916), including those that led the country during the bitter public debates that accompanied the enactment of the «secular laws» of the 1880s, saw in Christianity a fundamental element of «civilization» and in the Catholic Church a necessary ally for the construction of the nation, the state and the «progress». The article, based on ministerial and parliamentary sources, analyzes the consensus and dissent in the way in which the ruling elite conceived the agency of the Catholic clergy in the process of nation-building.
\end{abstract}

Keywords: Argentina, 19th century, nation, Catholicism, clergy

\section{INTRODUCCIÓN}

EN 1863 EL GOBIERNO ARgENTINO, por intermedio de su ministro de Justicia, Culto e Instrucción Pública, comunicó al Congreso que juzgaba «de suma importancia la formacion de un clero nacional digno é ilustrado, que, difundiendo en el pueblo, con su palabra y con su ejemplo, la práctica de la virtud y la moralidad de las costumbres, base de toda sociedad, coopere con la Autoridad 
Civil al afianzamiento de la paz y de las instituciones». ${ }^{1}$ La cita refleja las expectativas de las elites dirigentes en relación con el rol que debía desempeñar el clero católico en el proceso de construcción de la nación y en el afianzamiento del control del Estado sobre el territorio y sus habitantes.

El país se había unificado un año antes, con la elección de Bartolomé Mitre como presidente de la República, tras medio siglo de turbulencias políticas y de guerras internacionales y civiles. Enfrentadas a un territorio inabarcable y escasamente poblado, a sociedades dispersas a las que juzgaban sumidas en la «barbarie», esas elites esperaban contar con la agencia del clero para «civilizar» a las masas «con su palabra y con su ejemplo», mediante la difusión «de la práctica de la virtud y la moralidad de las costumbres» que constituían la «base de toda sociedad». Es significativo que, a diferencia de lo ocurrido en otros países, la mayor parte de los liberales argentinos no vieran al catolicismo como un obstáculo a remover para la formación de la nación, del Estado y de la economía capitalista, sino más bien al contrario: al asociar la «civilización» al cristianismo, conceptuado como religión de las «naciones cultas», la difusión de la fe y de la moral cristianas contribuiría a lograr el triunfo sobre la «barbarie» (Halperin Donghi, 1998; Di Stefano y Zanatta, 2000, p. 332). El clero católico tendría la doble misión de inocular el germen de la «civilización» en los argentinos —especialmente en las poblaciones rurales - y de asegurar la presencia del Estado en áreas en que su jurisdicción era frágil, como las vastas fronteras o las infinitas estepas patagónicas. El templo, el municipio y la escuela permitían congregar, en torno a incipientes núcleos urbanos, a la población dispersa en el «desierto»: los pobladores rurales, atraídos por la facilidad de acceso a los sacramentos y a los servicios administrativos

1 «Memoria presentada por el Ministro de Estado en el Departamento de Justicia, Culto é Instruccion Pública al Congreso Nacional de 1863-Buenos Aires» (1863, p. 8). 
que brindaban los párrocos — que conservaron el registro de las personas hasta 1884 , adoptarían al fin formas de sociabilidad «civilizadas». Se explica así por qué, en la Argentina decimonónica, los conflictos relacionados con la religión fueron más bien coyunturales y no constituyeron un importante clivaje político, así como el hecho de que el proceso de construcción del Estado haya comportado no el desmantelamiento, sino el fortalecimiento de las raquíticas instituciones eclesiásticas heredadas de la colonia. En cierto sentido, la construcción de la Iglesia católica argentina tal como la conocemos.

No por ello, sin embargo, la colaboración entre las jerarquías eclesiásticas y las elites dirigentes estuvo libre de tensiones y conflictos: la construcción nacional implicaba la imposición de una soberanía estatal excluyente, lo que complicaba las relaciones con una Iglesia que, en plena reforma ultramontana, afirmaba crecientemente su propia soberanía en el terreno espiritual, su carácter de «sociedad perfecta»y, por ende, su condición de institución independiente del Estado. Una Iglesia que, además, cuestionaba algunos de los principios basilares del Estado liberal-conservador, como lo eran la inherencia del patronato a la soberanía, el carácter meramente secular del poder político y la libertad de cultos. Así, por ejemplo, como tendremos ocasión de ver, la formación del «clero nacional» chocaría con el problema de que, en los seminarios, fundados en casi todos los casos por el Estado y financiados por el erario, se impartiesen «doctrinas subversivas» como las que contenían el Syllabus y otros documentos pontificios o conciliares de la época. Así, también, la implementación de leyes que esas elites juzgaban necesarias para el gobierno de una sociedad crecientemente plural en términos culturales y religiosos debería sortear la obcecada oposición de algunos dignatarios eclesiásticos —oposición considerada tanto más grave desde que el Estado veía en esos eclesiásticos a «funcionarios públicos»—.

El presente artículo analiza los consensos y los disensos que generó en las elites dirigentes argentinas la idea de que el clero católico estaba llamado a ocupar un rol relevante en el proceso de 
construcción nacional. El período estudiado transcurre entre 1862 y 1916, es decir, durante el período de la «organización nacional» (1862-1880) y bajo el llamado «régimen oligárquico» (1880-1916), cuando se sentaron las bases de la Argentina moderna y se debatieron los rasgos fundamentales de la laicidad del país. El marco teórico del trabajo considera a la Iglesia y al Estado no como entidades atemporales, sino como instituciones que adquirieron los rasgos esenciales de su fisonomía actual en el siglo XIX, producto de un doble proceso de construcción institucional que en la Argentina se dio de manera paralela y entrelazada (Di Stefano, 2011).

Por supuesto, claves son los conceptos de secularización, laicización y laicidad. Con respecto a ellos, dado que la bibliografía es infinita, me limitaré a señalar al lector un breve artículo en el que Jean Baubérot (2013) expone de manera concisa su significado. Agregaré solo que, en línea con contribuciones recientes de la sociología religiosa, se entiende aquí por secularización el pasaje de un régimen de unanimidad, en el que la religión impregnaba todos los órdenes de la vida, a un orden en el que lo religioso constituye una esfera propia y la creencia deviene objeto de elección libre. Es decir, no la desaparición o la marginalización de la religión, sino su recomposición en un diferente contexto. El concepto de laicización refiere al proceso por el cual el Estado logra autonomía política y administrativa respecto de la Iglesia, lo que conlleva la absorción estatal de funciones e instituciones hasta entonces controladas por las autoridades religiosas, como por ejemplo la educación, el registro de las personas, el matrimonio o la gestión de los cementerios. Puesto que en diferentes contextos nacionales encontramos diferentes tipos de laicidad, podemos decir que es esta una realidad múltiple, cambiante e inestable, resultado de las relaciones de fuerza entre los actores involucrados. Es decir, la laicidad no es una realidad siempre igual a sí misma, ni cristaliza de una vez y para siempre. Por último, es importante en este trabajo el concepto de "pacto laico» desarrollado por el mismo Baubérot (2001). Se trata de un acuerdo 
tácito que regula los conflictos que pudieran emerger entre los actores involucrados en la definición —y redefinición — de la laicidad, de modo de evitar que el enfrentamiento devenga frontal y tal vez violento (Baubérot, 2001). El texto se divide en tres parágrafos ordenados cronológicamente: el primero abarca el período de la organización nacional (1862-1880), el segundo se centra en la conflictiva década de 1880 y el tercero en el cambio de siglo.

\section{LA ORGANIZACIÓN NACIONAL}

Las presidencias de Bartolomé Mitre (1862-1868), Domingo F. Sarmiento (1868-1874) y Nicolás Avellaneda (1874-1880) se conocen en la historiografía argentina como «período de la organización nacional». La base jurídica de la unificación fue la Constitución de 1853, que en el plano religioso había establecido un régimen que combinaba la libertad de cultos con la desigualdad religiosa. Evitando declarar al catolicismo religión oficial, la Carta Magna le había concedido un estatus privilegiado a la Iglesia católica y había afirmado a la vez el derecho al ejercicio del patronato por parte del Estado nacional. Al mismo tiempo, había prescripto amplia libertad para el ejercicio de los cultos «disidentes», que por aquellos años se asociaban de manera automática a la condición de extranjería.

Durante esas tres gestiones gubernativas el consenso en torno a la necesidad de la agencia del clero en la construcción de la nación fue objeto de escasas y débiles impugnaciones. Pero ese consenso implicaba hacer frente a una realidad problemática en varios aspectos. Desde comienzos del siglo, el reclutamiento del clero secular había caído a niveles muy bajos y el del clero regular a niveles más bajos aún, problema que la Revolución y sus secuelas no habían hecho más que agravar. En Buenos Aires la escasez del clero nativo se había compensado, a partir de las décadas de 1830 y 1840, con la incardinación de eclesiásticos extranjeros, mayormente españoles, italianos e 
irlandeses. Pero ese clero extranjero, por el hecho mismo de serlo, no podía suplir al «clero nacional». Esa situación ponía sobre el tapete la cuestión de los seminarios, que en 1862 existían —quizás sería más apropiado decir que sobrevivían - solo en los obispados de Buenos Aires y de Córdoba, mientras las otras dos diócesis que había por entonces — las de Salta y Cuyo — carecían de ellos. Para revertir esa situación, el Congreso había sancionado en 1858 una ley, propuesta por el Poder Ejecutivo, que obligaba al gobierno nacional a crear seminarios en todos los obispados existentes y futuros. Ello pondría el problema, como veremos, del doble control, estatal y eclesiástico, que regía en los institutos que se crearon o se reorganizaron a partir de esa ley y de otras complementarias que fueron promulgadas durante las presidencias de Mitre y de Sarmiento.

Por otro lado, la Constitución obligaba al Estado a promover la conversión de los indígenas al catolicismo. Una de las razones de esa prescripción era la necesidad de legitimar el ejercicio del patronato nacional, dando continuidad a la tarea evangelizadora que había justificado el patronato regio. Pero fundamentalmente se buscaba la incorporación a la nación de los indígenas rebeldes del Chaco y de las vastedades pampeanas y patagónicas, lo que se lograría, en lo inmediato, convirtiéndolos al catolicismo, y en el largo plazo en ciudadanos y productores. Además, mientras duró la guerra, los misioneros cumplieron un papel importante en la redención de cautivos. En 1875 el Poder Ejecutivo Nacional creó el cargo de «inspector de misiones», considerando que «una larga experiencia» demostraba «que las reducciones de indios salvajes pueden convertirse, mediante una proteccion especial, en colonias agrícolas», y que «bajo la influencia de la educacion religiosa y moral, los salvajes llegan á aceptar la ley del trabajo y los hábitos de la vida regular, cultivando la tierra y prestando servicios de órden, en la defensa de 
las fronteras». ${ }^{2}$ Las misiones debían convertir a los indígenas en ciudadanos argentinos y asegurar la soberanía nacional en las fronteras.

Los gobiernos chocaron aquí con otra dificultad: la evangelización de los indígenas era una tarea para la cual era casi imposible contar con el clero secular, por lo que debieron recurrir necesariamente al regular. Ello contradecía un aspecto de las políticas eclesiásticas de esos gobiernos, que, en línea de continuidad con una tradición antigua, que hundía sus raíces en la era borbónica, tendían a favorecer al primero en detrimento del segundo, que presentaba mayores obstáculos al ejercicio de la soberanía y a la formación de la ciudadanía. Por otro lado, esas mismas políticas buscaban, como hemos visto, sustituir al clero extranjero por sacerdotes argentinos, escasos en el seno de las órdenes religiosas en la segunda mitad del siglo XIX. En consecuencia, esa doble preferencia por un clero secular y a la vez argentino fue imposible de sostener en el caso de las misiones, que las elites gobernantes debieron resignarse a confiar, por regla general, a órdenes y congregaciones integradas mayormente por sacerdotes europeos. Los franciscanos de Propaganda Fide que trabajaron en el Chaco y en la frontera sur de Córdoba y los salesianos — que a partir de 1879 se abocaron a la evangelización de la Patagonia - eran mayoritariamente italianos. Los redentoristas que se instalaron en Salta en 1883 provenían de Alemania; los lazaristas que misionaron entre los indígenas de Buenos Aires eran franceses. Se daba así la paradoja de que la tarea de incorporar a los indígenas a la «civilización argentina», su transformación en ciudadanos del nuevo país, recayera en las manos de eclesiásticos europeos.

La alternativa al clero extranjero era la formación de un «clero nacional». La voluntad de que ese clero fuese, en lo posible, secular, queda clara en la decisión de financiar con fondos del tesoro los seminarios y no las casas de formación de los religiosos, que

2 El texto del decreto en Memoria presentada al Congreso Nacional de 1876 por el ministro de Justicia, Culto é Instruccion Pública Doctor Onésimo Leguizamon (1876, pp. 54-55). 
carecieron de contribuciones regulares del presupuesto. Pero el carácter mixto —estatal y eclesiástico — de los seminarios generó problemas también. Fuente de reiterados conflictos fue el control de los contenidos de la enseñanza, que por una parte el Estado pretendía supervisar, en su calidad de fundador de la mayoría de los seminarios y en virtud de la financiación que les asignaba, y, por otra, se encontraban bajo jurisdicción del obispo por su carácter de «seminarios conciliares». En 1875, por ejemplo, el ministro de Culto consideró que «[e]l gobierno que costea esa enseñanza, en el interés de la ilustracion del clero nacional, tiene derecho á saber lo que se enseña y cómo se enseña en los referidos establecimientos». ${ }^{3}$ Dos años más tarde insistía sobre ese derecho: «Los Seminarios deben ser [...] establecimientos nacionales, sujetos á la inspeccion y vijilancia del Gobierno, como todos sus demás Colegios», porque «el verdadero fundador de estos establecimientos es el Estado y no la Iglesia». ${ }^{4}$ Las manifestaciones de los ministros en el mismo sentido fueron habituales hasta los años del «pacto laico» de fines de siglo, cuando significativamente comenzaron a desaparecer.

Se trataba, por un lado, de que la formación clerical respondiese a los parámetros de calidad de la época, comprendidas las materias que los pondrían al corriente de los «progresos científicos». En 1874, el ministro decía que los seminarios «se destinan á velar porque la instruccion del clero no se separe de los progresos modernos, para que estando en contacto con todas las corrientes de la vida, se inicie en los trabajos científicos y en los problemas principales que se tratan en ellos»..$^{5}$ Cuatro años más tarde su sucesor pedía al Congreso incrementar «las partidas destinadas al fo-

3 Memoria presentada al Congreso Nacional de 1875 por el ministro de Justicia, Culto é Instruccion pública Dr. D. Onésimo Leguizamon (1875, p. XXVIII).

4 Memoria presentada al Congreso Nacional de 1877 por el ministro de Justicia, Culto é Instruccion pública Dr. D. Onésimo Leguizamon (1877, p. XVI). Cursivas en el original.

5 Memoria presentada al Congreso de 1874 por el ministro de Justicia, Culto é Instruccion pública Dr. D. Juan C. Albarracin (1874, p. 26). 
mento de los Gabinetes de Física y Laboratorios de Química», al tiempo que subrayaba la importancia de dar, en el currículum de estudios, «la mayor estension á las ciencias naturales, sin descuidar, como es propio, las enseñanzas especiales, que caracteriza[n] á esas Instituciones»». ${ }^{6}$ Los pedidos de partidas presupuestarias y de útiles para los gabinetes y laboratorios, que los rectores de los seminarios y los obispos dirigían al ministerio, muestran que las autoridades eclesiásticas compartían esa preocupación por dar al clero una formación «moderna». En 1877 el ministro destacó esa coincidencia, que demostraba «el interés científico desarrollado en el seno del clero mismo». ${ }^{7}$

Por otra parte, no faltaban las denuncias de que en los seminarios se impartían enseñanzas «subversivas». Interesante al respecto es la discusión que tuvo lugar en 1875 en la Cámara de Diputados en referencia al seminario de la diócesis del Litoral, que funcionaba en el Colegio de la Inmaculada Concepción de los jesuitas en la ciudad de Santa Fe. Quienes objetaron ese año la partida presupuestaria argumentaron que el ministro ignoraba el modo en que se invertían los fondos del tesoro, que el erario destinaba una partida a un seminario inexistente y que se financiaba con ella un colegio jesuita. Los ignacianos eran considerados — con excelentes razones- los más decididos defensores de las tendencias ultramontanas que ganaban creciente espacio en el clero católico y que muchos juzgaban — también con excelentes razones - incompatibles con los principios basilares del Estado moderno. Tengamos en cuenta el contexto en que se entabló el debate: el 28 de febrero de ese año había tenido lugar el estallido anticlerical que concluyó con el incendio del colegio jesuita de Buenos Aires (Di Stefano, 2020). No estaba muy errado el diputado Milcíades Echagüe cuando sugirió

6 Memoria del Departamento de Justicia, Culto é Instruccion pública correspondiente al año de 1878 presentada al Honorable Congreso Nacional en sus sesiones de 1879 (1879, p. VII).

$7 \quad$ Memoria presentada al Congreso Nacional de 1877 (1877, p. XIX). 
que el verdadero problema era que el establecimiento pertenecía a la Compañía de Jesús: «y como estos habitantes [los jesuitas] está declarado que no tienen derecho de ciudadania y que deben ser quemados, quizá esta es la razon que hay para que se crea que este seminario no debe subsistir». ${ }^{8} \mathrm{Al}$ año siguiente, el diputado Miguel Cané (hijo) expresó lo que otros callaban: «Yo creo [...], respetando la religion y respetando á sus ministros, que la educacion que se recibe en los Colegios de Jesuitas, es la educacion mas nociva que puede recibir un niño destinado á ser ciudadano de un pais libre. Yo creo que todo Colegio de Jesuitas solo tiene un objeto: hacer jesuitas». ${ }^{9}$

Hemos visto en este apartado que, desde los comienzos de la organización nacional, existió un amplio consenso, en el seno de las elites gobernantes, en relación con la necesidad de contar con un «clero nacional» que coadyuvara a construir el nuevo país. La escasez de eclesiásticos «idóneos» — es decir, idealmente argentinos, «patriotas» y del clero secular — o la escasa disposición de muchos de ellos a hacerse cargo de ciertos destinos — como las misiones indígenas - obligó, sin embargo, a tolerar la presencia de sacerdotes que no gozaban de la mejor fama - extranjeros, muchos de ellos regulares, a menudo de dudosa moral — . La necesidad de formar ese clero nativo modélico que sustituyera gradualmente al extranjero indujo a los gobiernos «liberales» de Mitre y Sarmiento a fundar seminarios y a reorganizar los dos existentes. Pero allí las autoridades civiles encontrarían un nuevo escollo: el giro ultramontano de la Iglesia católica, que conllevaba la asunción de posturas críticas respecto de los fundamentos ideológicos de la modernidad, chocó con las ideas galicanas que predominaban en el elenco go-

8 Congreso Nacional. Diario de sesiones de la Cámara de Diputados. Año 1875 (1876, pp. 870-874: sesión del 25 de agosto de 1875, 879-890: sesión del 26 de agosto de 1875. La intervención de Echagüe en p. 883.

9 Congreso Nacional. Diario de sesiones de la Cámara de Diputados. Año 1876 (1877, p. 537, sesión del 5 de julio de 1876). 
bernante y que constituían el fundamento de la doble jurisdicción - estatal y eclesiástica - a la que estaban sujetos los seminarios. Las tensiones que generaron esas contradicciones, según veremos en el parágrafo que sigue, devinieron conflictos durante los debates de las «leyes laicas».

\section{LA DÉCADA «LAICISTA» DE 1880}

La década de 1880 asistió al momento de mayor conflictividad en las relaciones entre la Iglesia y el Estado en construcción. Los conflictos estallaron entre un sector mayoritario del Congreso, decidido a avalar el moderado programa de laicización del gobierno, y otro minoritario, identificado con las posiciones ultramontanas de las jerarquías eclesiásticas, que intentó frenarlo o al menos morigerarlo. Sin embargo, como veremos, aunque la cuerda se tensó, nunca llegó a cortarse.

El primer gran enfrentamiento se refirió a la cuestión educativa y tuvo lugar durante las deliberaciones del Congreso Pedagógico de 1882. En los años siguientes se debatieron y promulgaron tres leyes que son conocidas en la historiografía argentina como «leyes laicas»: la de educación común de 1884, la de creación del registro civil de ese mismo año y la de matrimonio civil de 1888. La primera prescribía que las clases de religión debían tener lugar fuera del horario escolar y ser impartidas no por los mismos maestros, sino por los ministros de los respectivos cultos, católico o protestantes. La ley tenía validez solo en las áreas de jurisdicción federal: la ciudad de Buenos Aires, capital del país, y los territorios nacionales. Es decir, no en las provincias, que conservaron la potestad de definir sus propios sistemas educativos. Mucho ruido provocó también la ley de matrimonio civil, porque imponía su obligatoriedad como requisito previo a cualquier matrimonio religioso. Los enfrentamientos tuvieron lugar en distintos ámbitos, desde la calle y la prensa hasta el ámbito 
parlamentario y las relaciones diplomáticas (el nuncio fue expulsado del país en 1884). En algunas provincias hubo actitudes de rebeldía por parte de feligreses, de párrocos o de la alta jerarquía eclesiástica (Auza, 1981; Cuccorese, 1981, 1982; Di Stefano y Zanatta, 2000).

En ese contexto, el rol del clero en la construcción nacional fue puesto en entredicho como nunca antes. Si la Iglesia resistía leyes votadas por el Congreso, estaba obstaculizando la construcción de la nación y del Estado. Para el gobierno, fiel en este punto a una antigua tradición galicana de raíces coloniales, los obispos, vicarios capitulares y hasta los curas eran «funcionarios públicos», lo cual volvía inadmisibles sus gestos de rebelión a las decisiones del poder federal. Fue sobre la base de esas consideraciones que el Poder Ejecutivo ordenó la destitución del vicario capitular del obispado de Córdoba y su reemplazo por otro eclesiástico.

El problema era la difusión del ultramontanismo en el seno del clero. Según el ministro de Culto Eduardo Wilde, la Argentina comenzaba «á sentir la inmigracion de hombres y de ideas incompatibles con los altos propósitos que persigue en su calidad de Estado moderno y civilizado». Ello se debía, al menos en parte, a que «los gremios eclesiásticos y las comunidades religiosas» europeas buscaban nuevos horizontes a causa de las restricciones que imponían a su labor «las naciones mas cultas». ${ }^{10}$ Es decir, el avance ultramontano guardaba cierta relación con la inmigración de clero regular extranjero. El colmo era que esas ideas nocivas se enseñasen en los seminarios creados y financiados parcialmente por el Estado nacional, varios de los cuales eran regenteados por los detestados jesuitas, extranjeros en su mayor parte. Como el Estado los había fundado y los financiaba, el gobierno se consideraba patrono de los seminarios, con todas las prerrogativas que el derecho concedía a quienes detentaban ese título. Por lo tanto, el Estado podía y debía

10 Memoria presentada al Congreso Nacional de 1884 por el ministro de Justicia, Culto e Instrucción pública Doctor Don Eduardo Wilde (1884, pp. 110-111). 
intervenir en la definición de los planes de estudio, o por lo menos impedir que en esos institutos se enseñasen doctrinas «subversivas».

Ese reclamo, que como vimos había comenzado a formularse hacia 1875, cobró inusitado vigor en 1884. En su informe al Congreso de ese año, el ministro, tras asegurar que durante el período que fenecía el gobierno había atendido adecuadamente las necesidades materiales de los seminarios, manifestó el disgusto oficial ante la negativa del rector de uno de ellos a elevar el informe anual sin previa autorización del obispo, «única autoridad que, segun él, tenia el derecho de enterarse de la marcha del Seminario». Reiteró que esos colegios eran de fundación estatal y que el gobierno, como fundador, tenía «todos los derechos inherentes al que funda una institucion». El gobierno no podía permitir que, en establecimientos auspiciados por el Estado, el clero se formase «bajo la impresion de ciertas teorías é incitaciones preconizadas en la Cátedra y que el Estado no podria menos que considerar subversivas, pues en algunos casos ellas contradicen las leyes del país o dificultan su rápida ejecucion». ${ }^{11}$

La cuestión se debatió en el Congreso en octubre. Durante la discusión de las partidas del presupuesto de culto para el año siguiente, el diputado Emilio Civit propuso suprimir todas las destinadas a los seminarios. Para fundamentar su postura argumentó que «la educacion que se dá en esos establecimientos no es científica, desde que se sabe [...] que la ciencia está en pugna con muchos de los dogmas y creencias que tiene la Iglesia». En su opinión, la educación que se impartía a los seminaristas era «tambien anti-religiosa, anti-cristiana»e incluso «anti-moral». La actitud reaccionaria que habían asumido el vicario capitular de Córdoba y el obispo de Salta al poner el Syllabus y las orientaciones pontificias por encima de la Constitución, la libertad, la conciencia y la razón, era un indicio

11 Memoria presentada al Congreso Nacional de 1884 (1884, pp. 151-157). 
de la enseñanza que se impartía en esos colegios. ${ }^{12}$ La discusión que desató su propuesta, acalorada y extensa, muestra que entre los mismos legisladores oficialistas no había consenso en la decisión de eliminar las partidas. A título de ejemplo podemos citar la intervención de Delfín Gallo, uno de los más decididos defensores de las «leyes laicas», quien se opuso con denuedo a la propuesta de Civit. Aunque Gallo coincidió en que se hallaba en sus inicios una larga lucha de la libertad contra las doctrinas «funestas» de los ultramontanos, se opuso a la supresión de las partidas argumentando su carácter anticonstitucional (por la prescripción de la Carta Magna de sostener el culto católico) y su inconveniencia política: justamente a causa de esa larga lucha de la libertad contra el ultramontanismo, el control estatal de los seminarios era preferible a su abandono en manos de los obispos. Por otra parte, dado que el Estado se había comprometido a ayudar a formar a los sacerdotes, debía bregar por que se educasen como patriotas. Repitiendo el antiguo estribillo, afirmó que sin clero nacional el país contaría solo con el denostado clero extranjero. ${ }^{13}$

Finalmente, las partidas para los seminarios fueron eliminadas del presupuesto de 1885. Sin embargo, al año siguiente, en un clima político parejamente tenso, fueron repuestas sobre la base de las mismas consideraciones de siempre: la necesidad de un clero nacional idóneo y patriota para la construcción de la nación. A partir de entonces, además, se las siguió votando cada año, y a pesar de que las leyes de registro civil y matrimonio civil recortaron los efectos civiles de la acción de los curas, su influencia en la formación de la sociedad argentina siguió considerándose relevante y la calidad de su formación moral e intelectual siguió reputándose una cuestión

12 Congreso Nacional, Diario de sesiones de la Cámara de Diputados, año 1884, tomo segundo (1885, pp. 226-227, sesión del 7 de octubre de 1884).

13 Congreso Nacional, Diario de sesiones de la Cámara de Diputados, año 1884, tomo segundo (1885, pp. 231-233). 
de Estado. Así, en la Memoria presentada al Congreso de 1885 el mismo ministro Wilde diagnosticó que:

[...] el mal proviene de la manera cómo se forma el Clero Arjentino, del sistema implantado en los Seminarios, que dá por resultado la singularidad de que ese Clero, educado é instruido á expensas del erario Nacional, posea un conocimiento tan incompleto de las instituciones y de sus deberes para con el país de su nacimiento, como el que adquiere la mayor parte del Clero extranjero que solo sabe que el Gobierno sostiene su culto y que la patria quedó en el otro lado del Océano. ${ }^{14}$

$\mathrm{Al}$ año siguiente Wilde volvió a lamentar que, a pesar de contar el país con cinco seminarios, los curas fuesen «casi todos extranjeros, muchos de ellos ineptos, algunos completamente ignorantes y no pocos grotescos y ridículos que convierten la cátedra sagrada en un objeto de mofa. El que quiera convencerse de esto, no tiene mas que recorrer algunos pueblos de campaña y oir los sermones que el clero cosmopolita predica en un idioma que no existe». Así las cosas, el ministro dudaba de que el beneficio que habían reportado al país los seminarios, justificase su fundación y financiación estatal. Sin embargo, admitía que la República Argentina necesitaba a los sacerdotes, y por ende el gobierno debía ocuparse del buen funcionamiento de esos institutos. ${ }^{15}$ De hecho, los discursos respecto de la contribución del clero a la construcción de la nación continuaron repitiéndose año a año, en cada memoria del Departamento de Culto y en todos los debates parlamentarios. Aunque en 1887 el nuevo ministro, Filemón Posse, en línea con el discurso de su predecesor, afirmó que el clero argentino, salvo excepciones, no estaba a la altura de su misión — si lo estuviera, dijo, no reinaría en las masas «un

14 Memoria presentada al Congreso Nacional de 1885 por el Ministro de Justicia, Culto é Instrucción Pública Dr. D. Eduardo Wilde (1885, pp. XXXII-XXXIII). Cursivas en el original.

15 Memoria presentada al Congreso Nacional de 1886 por el Ministro de Justicia, Culto é Instrucción Pública Dr. D. Eduardo Wilde (1886, pp. XXVIII-XXX). 
rudo fanatismo»—, subrayó una vez más la influencia «omnímoda» que el clero ejercía «en la clase poco ilustrada del pueblo» y la consecuente necesidad de lograr que esa influencia «en vez de perniciosa sea benéfica», lo que solo podía lograrse mediante la indispensable formación de «un clero ilustrado». ${ }^{16}$

Lo curioso es que, a esa altura, contra lo que habría cabido esperar, el clero misionero, casi por definición europeo, a los ojos del gobierno presentaba menos problemas y prestaba mayores servicios que el clero nativo secular. El expresidente Roca había «conquistado para la civilizacion el inmenso y feraz territorio ocupado antes por los salvajes», y ahora el Estado tenía el deber de «conquistar esos salvajes para la vida civilizada, promoviendo su conversion al catolicismo, como lo ordena la Constitucion». Contrariamente a cuanto ocurría con los seminarios, que contra las expectativas oficiales no formaban un clero secular suficiente e idóneo para atender las necesidades del país, las misiones entre los indígenas, que percibían del Estado «una suma demasiado pequeña», ofrecían resultados «relativamente grandes». Los misioneros de la Patagonia, salesianos italianos, habían catequizado a dos mil indios, habían fundado un colegio de niños y otro de niñas con doscientos alumnos cada uno y hasta habían erigido una escuela de artes y oficios. El éxito de esas misiones, según el ministro, no podía ser «mas halagador»: «Allí donde solo reinaba la barbarie — dijo- se están levantando poblaciones civilizadas». ${ }^{17}$ El gobierno de Juárez Celman (1886-1890), que promovió la ley de matrimonio civil, incrementó la asistencia estatal a esas misiones de sacerdotes regulares casi unánimemente extranjeros, celebró sus logros y lamentó no poder asignarles mayores recursos financieros. ${ }^{18}$

\footnotetext{
16 Memoria presentada al Congreso Nacional de 1887 por el Ministro de Justicia, Culto é Instrucción Pública Dr. D. Filemón Posse (1887, pp. XXV-XXVI).

17 Memoria presentada al Congreso Nacional de 1887 (1887, p. XXVII).

18 Memoria presentada al Congreso Nacional de 1889 por el Ministro de Justicia, Culto é Instruccion Pública Dr. D. Filemon Posse (1889, pp. XXVII-XXVIII).
} 
Las misiones eran importantes, como hemos visto, para afirmar la soberanía y la presencia del Estado nacional en áreas en que eran poco más que nominales. Con ese mismo objetivo, en diciembre de 1883 el gobierno «laicista» de Roca había creado la parroquia del Territorio Nacional de Misiones, siguiendo las recomendaciones del procurador general de la nación, el célebre anticlerical Eduardo Costa: se trataba de evitar que sus habitantes, «próximos [...] á las fronteras del Brasil [se vieran] en la necesidad de solicitarlo [el servicio pastoral] de los curatos de este». ${ }^{19}$ Por otro lado, en definitiva, los redentoristas, los franciscanos de Propaganda Fide o los salesianos que regenteaban las misiones resultaban, en esa coyuntura signada por las controversias en torno a la laicidad, menos problemáticos que los obispos y vicarios capitulares que oponían resistencia al moderado empuje laicista.

Podríamos multiplicar los testimonios, pero todos nos llevarían al mismo punto: ni siquiera durante los años más álgidos del enfrentamiento entre los sectores ultramontanos y los más decididamente laicistas de las elites gobernantes fue puesta en entredicho la relevancia de la acción del clero en el proceso de la construcción de la nación. Lo que se puso en cuestión fue la calidad de la formación del clero secular, pero la solución que hallaron gobiernos y legisladores no fue dejar los seminarios a merced de los obispos, sino seguir financiándolos con la esperanza de que se elevasen a la altura de esa misión. Si en 1884 el Congreso eliminó las partidas presupuestarias para los seminarios por las ideas «subversivas» que en ellos se inoculaban en los seminaristas, al año siguiente los subsidios se repusieron y se conservan hasta la actualidad. Por otro lado, aunque el clero regular y el clero extranjero solían ser mirados con suspicacia e incluso estigmatizados, en la coyuntura de la finaliza-

19 «Decreto erigiendo en Parroquia Eclesiástica, interinamente, el Territorio de Misiones é incorporada á la Diócesis del Litoral», 6 de diciembre de 1883, en Memoria presentada al Congreso Nacional de 1884 (1884, pp. 390-391). 
ción de la guerra de conquista del «desierto» el trabajo de los misioneros europeos fue valorado como una contribución importante a la construcción de la nación. La elite gobernante, aun en esos años en que predominaron en su seno las voces más críticas de la Iglesia, siguió asociando la nacionalización de los indígenas con su conversión al cristianismo.

\section{EL «PACTO LAICO»}

Las turbulencias de la década de 1880 se apaciguaron en la siguiente. En 1892 el católico Juan Balestra, ministro de Culto del presidente Carlos Pellegrini (1890-1892), no se limitaba a reconocer la necesidad de contar con un clero nacional idóneo, sino que subrayaba la importancia intrínseca de la religión, especialmente «en momentos de transformación social» como los que atravesaba el país. Por eso, según informaba a los parlamentarios, deseaba evitar toda controversia que pudiese alterar «el statu quo que los hechos han impuesto en las relaciones de la autoridad civil y la eclesiástica» y acordar toda la asistencia pecuniaria posible a «templos, obras pías, asociaciones caritativas, misiones civilizadoras, etc.». Con respecto a la formación del clero nacional, el ministro hacía suyos los lugares comunes que ni siquiera sus antecesores anticlericales habían abandonado: los sacerdotes que se formasen en los seminarios argentinos, por deficiente que fuera la instrucción que se impartía en ellos, siempre serían mejores que «los que pululan [por] nuestras campañas, sacerdotes venidos de otras naciones que, si bien profesan el culto de Dios, no conocen ni profesan el culto y el amor á la patria argentina, del que no pueden prescindir nuestros Seminaristas». ${ }^{20}$

\footnotetext{
20 Memoria presentada al Congreso Nacional de 1892 por el ministro de Justicia, Culto é Instrucción Pública Dr. D. Juan Balestra (1892, pp. CXXX-CXXXII).
} 
En el cambio de siglo, durante la segunda presidencia de Julio A. Roca (1898-1904), se restablecieron las relaciones con la Santa Sede que el mismo Roca había interrumpido durante la primera (1880-1886). En esos años, a las condiciones que desde siempre habían aconsejado contar con el clero católico para la «civilización del país» y construir la nación, se sumó la preocupación de las elites dirigentes en relación con dos problemas inquietantes: la identidad nacional, amenazada — según creían — por la inmigración de masas, y la emergente «cuestión social», consecuencia de las míseras condiciones de vida de muchos habitantes, de la creciente organización sindical y de la acción de los «maximalistas». Ya Balestra, como acabamos de ver, destacaba en 1892 la relevancia de la religión en momentos de fuerte «transformación social». Frente a esas realidades, y frente a un pontificado que con el desarrollo de la doctrina social de la Iglesia ofrecía posibles soluciones a los conflictos sociales — como la mediación del Estado y la organización obrera libre de influencias «subversivas», por ejemplo_-, las elites gobernantes y las jerarquías eclesiásticas suscribieron un tácito "pacto laico», en cuya virtud las primeras renunciaron a avanzar de manera sensible en el camino de la laicización —ante todo desoyendo las recurrentes propuestas de separación jurídica de la Iglesia y el Estado- y las segundas aceptaron adaptarse, en la medida de lo posible, al estado de cosas vigente (Di Stefano, 2012).

En ese contexto, los discursos referidos a la necesidad del «clero nacional» cobraron renovados impulsos. Es significativa, por ejemplo, la insistencia en proporcionarle modelos a imitar tomados del pasado, preocupación compartida entre la jerarquía eclesiástica y numerosos legisladores y hombres de gobierno: los sacerdotes argentinos, para cumplir con su misión a la vez pastoral y patriótica, debían mirarse en el espejo de los que habían tomado parte en la Revolución de independencia — aquellos «curas de aldea» que en el Congreso de Tucumán habían suscripto la independencia en 1816- Comenzó así a cobrar cuerpo una especie de panteón de 
«sacerdotes ejemplares» que hasta algunos anticlericales admitieron venerar. El punto culminante de ese proceso de construcción discursiva se verificó en los años que corrieron entre el Centenario de la Revolución (1910) y el de la declaración de la independencia (1916), durante los cuales los católicos intentaron, con bastante éxito, reescribir la historia de los orígenes de la nación en clave confesional (Di Stefano, 2003). A las figuras ejemplares del clero revolucionario se sumó la de fray Mamerto Esquiú (1826-1883), un obispo considerado digno de ser admitido en ese panteón por haber exhortado a los católicos a obedecer la Constitución de 1853, a pesar de las cláusulas —en especial la libertad de cultos — que atentaban contra los «derechos de la Iglesia». Lo que se pedía al «clero nacional» era que, a imitación de los curas revolucionarios y de Esquiú, sirvieran a la patria y a la Iglesia con parejo fervor.

Los ejemplos son numerosos. El diputado anticlerical Andrónico Castro, que no se cansaba de proclamar a los cuatro vientos que el clero era un hatajo de parásitos que vivía del sudor de los pobres, dijo en 1887 que el país necesitaba «sacerdotes virtuosos y modestos como Esquiú»». ${ }^{21}$ Años más tarde su colega cordobés Eleazar Garzón pidió un clero nacional como el que, desde 1810, contrariando la postura reaccionaria de Roma, había luchado por la Revolución. ${ }^{22}$ En vísperas del cambio de siglo, el sacerdote y diputado Gregorio Romero reivindicó a los eclesiásticos argentinos del pasado, que de Pedro Ignacio de Castro Barros (1777-1849) a fray Mamerto Esquiú podían considerarse, según creía, verdaderos precursores de la «democracia cristiana» que promovía el papa León XIII. ${ }^{23}$ En 1909 el senador Francisco Figueroa, en un enésimo dis-

21 Congreso Nacional, Diario de sesiones de la Cámara de Diputados, año 1887 (1888, p. 722, sesión del 3 de noviembre de 1887).

22 Congreso Nacional. Diario de sesiones de la Cámara de Diputados, 1894 (1894, p. 1160, sesión del 19 de diciembre de 1894).

23 Congreso Nacional. Diario de sesiones de la Cámara de Diputados, año 1898, sesiones de prórroga (1899, p. 760, sesión del 4 de enero de 1899). 
curso dirigido a subrayar la importancia de la formación del «clero nacional», evocó a los sacerdotes de la Revolución de independencia y a fray Mamerto Esquiú. ${ }^{24}$

Sin embargo, desde el crepúsculo de la centuria, y con particular estridencia durante las primeras décadas del siglo XX, se multiplicaron también, en las cámaras como en la prensa, las voces críticas del clero y de su supuesta influencia benéfica para el país. Los cuestionamientos se dirigieron especialmente, como antaño, hacia el clero regular y hacia los extranjeros. Es que, como efecto inesperado - y para muchos indeseado - de la inmigración europea que afluyó masivamente a la Argentina en esos años, se radicaron en el país numerosas congregaciones y órdenes oriundas de diversos países del Viejo Mundo. Dedicadas a la consecución de diferentes fines, como la educación y la asistencia pastoral de determinadas comunidades de inmigrantes, muchos de esos institutos buscaron refugio en la Argentina ante las restricciones que se les imponían en sus países de origen. Esa afluencia de regulares encendió la alarma de algunos medios anticlericales, que vieron en ella una suerte de invasión de funestas consecuencias: la «escoria» descartada por las naciones adelantadas de Europa buscaba establecerse en el país para beneficiarse de su opulencia.

Así, las primeras dos décadas del siglo XX asistieron a un recrudecimiento de las invectivas contra el clero regular europeo. En 1901 el diputado Emilio Gouchon presentó un proyecto de ley que preveía inspecciones semestrales de las órdenes religiosas por parte de funcionarios del Estado. El clero regular, dijo, era por sus características nefasto para la Argentina: «el primer voto que formula el monje, señor presidente, es contrario á las necesidades de nuestra nación. La pobreza, como fin de la existencia, como condición de ella misma, perjudica notablemente la economía de una nación».

24 Congreso Nacional, Diario de sesiones de la Cámara de Senadores, año 1909, sesiones ordinarias (1909, p. 870, sesión del 22 de septiembre de 1909). 
Parte del dinero que ingresaba en los conventos, agregó, salía del país para engrosar las arcas de las casas superiores de los institutos en Europa. Cuando Gouchon dijo que el segundo voto era la castidad, provocó en la cámara un estallido de risas irreverentes. El tercer voto, el de obediencia, según el legislador implicaba «la renuncia a la propia voluntad, la obediencia ciega. Esto importa la negación de la personalidad humana. [...] La obediencia ciega, señor presidente, es la reducción del hombre á la condición de la cosa, á la condición de esclavo». La conclusión de todo ello se caía de madura: mientras antiguamente «se explicaba que entre el mal de una sociedad corompida, ociosa y sin medios de vida, el hombre buscase la soledad del convento [...] hoy los términos han cambiado completamente: si antes la sociedad podía escandalizar al convento y hacerle huir de ella, hoy, por el contrario, es la sociedad la que se escandaliza del convento». Y dado que «no hay interés ninguno para el estado en conservar esas órdenes, sino que, por el contrario, el estado se encuentra perjudicado por ellas, deben desaparecer todas las regalías que las leyes actuales les conceden». ${ }^{25}$ En ocasiones esas voces de alarma adquirieron tonalidades delirantes, como cuando en 1910 el diputado anticlerical Carlos Conforti habló de «la posibilidad de que emigren en masa congregacionistas, órdenes ó instituciones de religiosos de distintos puntos de Europa á la República Argentina, y se ha anunciado una invasión de dos mil sacerdotes regulares que por lo pronto están listos para embarcarse en Portugal». ${ }^{26}$

Esos nuevos críticos de los «frailes», al igual que sus adversarios «clericales», hurgaron en el pasado en busca de ejemplos que ofrecieran sustento a sus posturas. Varios opúsculos de carácter histórico fueron publicados en esos años para denostar la vida conven-

25 Congreso Nacional, Diario de sesiones de la Cámara de Diputados, año 1901 (1901, pp. 467-468, sesión del 14 de agosto de 1901, pp. 467-468).

26 Congreso Nacional, Diario de sesiones de la Cámara de Diputados, año 1910 (1910, p. 784, sesión del 14 de agosto de 1910, p. 784). 
tual, que fue condenada también en algunas piezas literarias: en su poema «La leyenda argentina» Joaquín Castellanos, en polémica con el hispanismo que ganaba espacios en la cultura argentina, recordó a las «turbas de aventureros» que durante la conquista se habían lanzado en busca de riquezas «[c] on la cruz en el puño de la espada,/ Y la espada homicida/ Por el fraile canalla bendecida» (Castellanos, 1910, p. 322).

Algunos parlamentarios extremaron sus críticas hasta descalificar no solo al clero, sino al propio catolicismo. Para algunos socialistas la acción de la Iglesia, lejos de coadyuvar a la construcción de la nación, deformaba intelectual y moralmente a sus ciudadanos. En 1912, el diputado socialista Juan B. Justo dijo que:

Los judíos, a los niños recién nacidos que incorporan a su iglesia, les cortan cierta parte de la piel, en un rito sangriento y bárbaro, y creen cumplir así una ley religiosa. La iglesia católica los somete a una mutilación más grave: les mutila a los niños el alma, engendra en ellos la hipocresía, porque desde el momento en que al niño se le ejercita en el mero cumplimiento de formas externas, se le desarrolla el hábito de la simulación. Esas son escuelas de malos patriotas, de ciudadanos que han de jurar por la bandera y han de engañar al pueblo, y han de corromperlo siempre que les convenga. El patriotismo de esas escuelas ha de ser como la caridad de una hermana que vi en el hospital negar el agua a un moribundo porque no se confesaba. ${ }^{27}$

Con todo, la mayoría de los legisladores y el Poder Ejecutivo, representado desde 1899 por el ministro de Relaciones Exteriores y Culto, siguieron exaltando la función «civilizadora» del clero y votando subvenciones para congregaciones y órdenes que no gozaban de partidas fijas en el presupuesto. Los argumentos que esgrimían para ello se resumen en dos: por un lado, la Constitución nacional prescribía el «sostén del culto católico», por lo que los reclamos contrarios a la financiación estatal contradecían los mandatos de la

27 De Madrid (1914). 
Carta Magna. Por otro, el aumento de la población y la formación de nuevos pueblos, que en esos años surgían como hongos por todo el país, generaba necesidades que el Estado no estaba en condiciones de satisfacer. Por ejemplo, en 1910, el diputado mendocino Pedro Guevara de Mendoza pidió un subsidio para las hermanas mercedarias de caridad, que en su provincia habían creado una escuela para niños pobres, alegando que «los colegios fiscales no bastan á contener todos los niños que se hallan en estado de recibir educación en Mendoza». ${ }^{28}$ Ese mismo año el diputado salteño Felipe Guasch Leguizamón, masón y miembro de la Liga Argentina de Librepensamiento, reconocía que la escuela pública no podía proporcionar educación a todos los niños, ni siquiera en la Capital Federal. ${ }^{29}$ Esa falencia era, desde luego, mucho más acentuada en los territorios de reciente colonización, como muestra paradigmáticamente el caso pampeano-patagónico.

\section{Conclusiones}

Por los motivos que fueran - convicción religiosa o cálculo político, según los casos_-, entre 1862 y 1916 hubo un sustancial consenso, en el seno de las elites dirigentes argentinas, en torno a la necesidad de contar con el clero católico para la construcción de la nación. Para el liberalismo argentino del siglo XIX, esa misión histórica se identificaba con la derrota de la «barbarie» y la victoria de la «civilización», concebida como un conjunto de valores morales, hábitos de laboriosidad y formas de sociabilidad que se identificaban con la cultura europea — especialmente la de las «naciones del

28 Congreso Nacional, Diario de sesiones de la Cámara de Diputados, año 1910 (1910, p. 784).

29 Congreso Nacional, Diario de sesiones de la Cámara de Diputados, año 1910 (1910, p. 521). 
norte de la Europa»—y con el cristianismo. Este era, más que una fe religiosa, el basamento moral de las naciones que se encontraban a la vanguardia del progreso humano. De hecho, para algunos legisladores era relativamente indiferente que los indios fueguinos fueran convertidos al catolicismo por los salesianos italianos o al anglicanismo por los misioneros de la Iglesia de Inglaterra, y no pocos preferían la influencia protestante a la católica (Seiguer, 2017, p. 49).

La realidad, sin embargo, era que la mayoría de los habitantes del país profesaba el catolicismo o era nominalmente católica, rasgo que, lejos de verse desdibujado, se vio reforzado por la inmigración masiva de origen europeo, proveniente, en su abrumadora mayoría, de países latinos. Además, más allá de la prescripción constitucional del «sostén del culto católico», la expansión demográfica, crecientemente acelerada a lo largo y ancho de un territorio siempre inabarcable, creaba necesidades que el Estado en construcción no podía satisfacer por sí mismo, como muestran los ejemplos de la educación, del registro civil y de las misiones.

Así, el interés por la formación del «clero nacional» y los recursos destinados a los seminarios no mermaron ni siquiera durante la década de 1880, el período de mayor empuje laicista y de mayor optimismo en relación con el futuro «laico» de la «república verdadera», con el triunfo de la ciencia y con el avance inexorable de un progreso que supuestamente opacaría la fe religiosa. Es significativo que, en esos mismos años, los clásicos discursos adversos a los «frailes» — como se llamaba despectivamente a los religiosos_ cedieran espacio a una valoración positiva de los servicios que órdenes y congregaciones ofrecían en el terreno misional, ámbito al que el sometimiento de los grupos indígenas del Chaco y de la Pampa-Patagonia confería entonces particular relevancia. Es decir, ni siquiera durante el ápice de las polémicas en torno al proceso de laicización desapareció el interés de las elites dirigentes en la agencia del clero católico, e incluso, a la luz de su desempeño en las vastas regiones recientemente conquistadas, se debilitaron los motivos para denostar a los 
religiosos extranjeros. Más allá de las convicciones personales de ministros y legisladores —Eduardo Wilde, Onésimo Leguizamón, Delfín Gallo, Felipe Guasch Leguizamón y otros protagonistas de esta historia eran anticlericales y masones-, la política de Estado fue apostar a la colaboración del clero católico en la tarea de construir la nación.

El ejemplo de la implementación del matrimonio civil es sumamente elocuente: a partir de la promulgación en 1888 de la ley que lo creó, le otorgó carácter obligatorio y despojó al matrimonio religioso de efectos civiles, el elenco gobernante empezó a descubrir que en algunas zonas las oficinas del registro civil distaban tanto entre sí que las parejas debían viajar varios días para poder casarse. Los obispos, por su parte, no se cansaban de denunciar que desde la entrada en vigor de la ley los amancebamientos se habían multiplicado, sobre todo en el campo. Esa cruda realidad obligó al Estado a permitir que los curas y misioneros pudiesen actuar como agentes del registro civil allí donde hiciera falta, al tiempo que otras crudas realidades incidían en otros aspectos que hacían a la labor del clero en vastas áreas del territorio: los salesianos, que por su carácter de congregación italiana, eran objeto por partida doble de las diatribas que tradicionalmente se dirigían a los regulares y a los sacerdotes extranjeros, se revelaron indispensables como misioneros y como educadores en la Pampa Central y en la Patagonia (Rodríguez, 2009, 2014, 2016). Los redentoristas y franciscanos de Propaganda Fide, que reunían las mismas características, eran indispensables como misioneros entre los indios del Chaco, a los que el «clero nacional» no se habría acercado ni a punta de pistola.

A partir del cambio de siglo se incrementaron, por cierto, las voces críticas de la Iglesia. Senadores y sobre todo diputados que se autoproclamaban «librepensadores» — o pertenecían a la bancada socialista-cuestionaron el tradicional consenso en torno a la necesidad del clero para la construcción de la nación y hasta llegaron a denostar la influencia católica. Pero la cruda realidad, nuevamente, se 
encargó de esterilizar muchas de sus iniciativas legislativas y confinó al cajón de los imposibles «la campaña que ha de cortar todo vínculo entre el Estado argentino y todas las iglesias y sectas, la campaña que ha de realizar definitivamente entre nosotros la igualdad de las creencias ante la ley». ${ }^{30}$ Por entonces, los temores de las elites frente a la inmigración de masas y la acción de partidos y grupos de izquier$\mathrm{da}$, especialmente anarquistas, agregaban ulteriores motivos para la búsqueda de la colaboración eclesiástica y para abandonar el proceso de laicización de la década de 1880. Una postura que la crisis del liberalismo del período de entreguerras se encargará de fortalecer.

\section{REFERENCIAS}

\section{FUENTES PRIMARIAS}

Castellanos, Joaquín (1910). «La leyenda argentina». En: Antología de poetas argentinos por Juan de la C. Puig, Tomo X: «Auroras y ocasos». Buenos Aires: Martín Biedma.

Congreso Nacional. Diario de sesiones de la Cámara de Diputados. Año 1875 (1876). Tomo primero. Buenos Aires: Imprenta de Pablo E. Coni.

Congreso Nacional. Diario de sesiones de la Cámara de Diputados. Año 1876 (1877). Tomo primero. Buenos Aires: Imprenta de Mayo.

Congreso Nacional. Diario de sesiones de la Cámara de Diputados, año 1884, tomo segundo (1885). Sesión del 7 de octubre de 1884. Buenos Aires: Imp. y Encuad. de Stiller \& Laass.

Congreso Nacional, Diario de sesiones de la Cámara de Diputados, año 1887 (1888). Tomo segundo. Buenos Aires: Imprenta La Universidad.

Congreso Nacional. Diario de sesiones de la Cámara de Diputados, 1894 (1894). Tomo II. Buenos Aires: Imprenta del Congreso.

30 Juan B. Justo en la Cámara de Diputados, 27 de septiembre de 1912 (De Madrid, 1914, p. 200). 
Congreso Nacional. Diario de sesiones de la Cámara de Diputados, año 1898, sesiones de prórroga (1899). Buenos Aires: Compañía Sud-Americana de Billetes de Banco.

Congreso Nacional. Diario de sesiones de la Cámara de Diputados, año 1901 (1901). Tomo I. Buenos Aires: Establecimiento Tipográfico «El Comercio».

Congreso Nacional. Diario de sesiones de la Cámara de Diputados, año 1910 (1910). Tomo II. Buenos Aires: Establecimiento Tipográfico «El Comercio».

Congreso Nacional. Diario de sesiones de la Cámara de Senadores, año 1909, sesiones ordinarias (1909). Buenos Aires: Establecimiento Tipográfico «El Comercio».

De Madrid, Samuel (1914). El gobierno enfermo, Buenos Aires: Talleres Gráficos de Selín Suarez.

Memoria del Departamento de Justicia, Culto é Instruccion pública correspondiente al año de 1878 presentada al Honorable Congreso Nacional en sus sesiones de 1879 (1879). Buenos Aires: Imprenta de «El Nacional».

Memoria presentada al Congreso de 1874 por el ministro de Justicia, Culto é Instruccion pública Dr. D. Juan C. Albarracin (1874). Buenos Aires: Imprenta de la Sociedad Anónima.

Memoria presentada al Congreso Nacional de 1875 por el ministro de Justicia, Culto é Instruccion pública Dr. D. Onésimo Leguizamon (1875). Buenos Aires: Imprenta Americana.

Memoria presentada al Congreso Nacional de 1876 por el ministro de Justicia, Culto é Instruccion Pública Doctor Onésimo Leguizamon (1876). Buenos Aires: Imprenta de «El Tribuno».

Memoria presentada al Congreso Nacional de 1877 por el ministro de Justicia, Culto é Instruccion pública Dr. D. Onésimo Leguizamon (1877). Buenos Aires: Imprenta y Litografía del «Courrier de La Plata» [sic]. 
Memoria presentada al Congreso Nacional de 1884 por el ministro de Justicia, Culto e Instrucción pública Doctor Don Eduardo Wilde (1884). Tomo I-Texto. Buenos Aires: Imprenta de «La Tribuna Nacional».

Memoria presentada al Congreso Nacional de 1885 por el Ministro de Justicia, Culto é Instrucción Pública Dr. D. Eduardo Wilde (1885). Buenos Aires: Taller Tipográfico de la Penitenciaria.

Memoria presentada al Congreso Nacional de 1886 por el Ministro de Justicia, Culto é Instrucción Pública Dr. D. Eduardo Wilde (1886). Tomo I. Buenos Aires: Taller Tipográfico de la Penitenciaria.

Memoria presentada al Congreso Nacional de 1887 por el Ministro de Justicia, Culto é Instrucción Pública Dr. D. Filemón Posse (1887). Tomo I-Texto. Buenos Aires: Taller Tipográfico de la Penitenciaria.

Memoria presentada al Congreso Nacional de 1889 por el Ministro de Justicia, Culto é Instruccion Pública Dr. D. Filemon Posse (1889). Tomo I. Buenos Aires: Taller Tipográfico de la Penitenciaría.

Memoria presentada al Congreso Nacional de 1892 por el ministro de Justicia, Culto é Instrucción Pública Dr. D. Juan Balestra (1892). Tomo I. Buenos Aires: Compañía Sud-Americana de Billetes de Banco.

«Memoria presentada por el Ministro de Estado en el Departamento de Justicia, Culto é Instruccion Pública al Congreso Nacional de 1863-Buenos Aires» (1863). En: Mensaje del Poder Ejecutivo Nacional y Memorias respectivas de los Departamentos de Relaciones EsterioresInterior-Hacienda-Culto, Justicia é Instruccion Pública-Guerra y Marina presentadas al Congreso Nacional de 1863. Buenos Aires: Imp. del «Comercio del Plata», p. 8.

\section{FUENTES SECUNDARIAS}

Auza, Néstor T. (1981). Católicos y liberales en la Generación del Ochenta. Buenos Aires: Ediciones Culturales Argentinas.

Baubérot, Jean (2001). «La laïcité comme pacte lä̈que». En: Jean Baudouin y Phillipe Portier (eds.). La laïcité, une valeur d'aujourd'bui? Rennes: Presses universitaires de Rennes, pp. 39-50. 
BAubÉrot, Jean (2013). «Sécularisation, laïcité, laïcisation». Empan, 2013/2, núm. 90, pp. 1-38. Disponible en https://www.cairn.info/revueempan-2013-2-page-31.htm. Fecha de acceso: 6 de abril de 2020.

CucCorese, Horacio J. (1981). «Historia de las Ideas. La cuestión religiosa a través de los debates del Congreso Pedagógico de 1882». Investigaciones y Ensayos, núm. 30, pp. 105-160.

Cuccorese, Horacio J. (1982). «Polémicas de campanillas: la "cuestión religiosa" a principios de 1883. Historia de las ideas en la Argentina». Investigaciones y Ensayos, núm. 32, pp. 105-157.

Di Stefano, Roberto (2003). «De la teología a la historia: un siglo de lecturas retrospectivas del catolicismo argentino». Prohistoria, núm. 6, pp. 173-201.

Di Stefano, Roberto (2011). «Por una historia de la secularización y de la laicidad en la Argentina». Quinto Sol, vol. 15, núm. 1, pp. 1-32. Disponible en: http://historiapolitica.com/datos/biblioteca/distefano_cyp. pdf. Fecha de acceso: 18 de noviembre de 2019.

Di Stefano, Roberto (2012). «El pacto laico argentino» [en línea]. PolHis. Boletín Bibliográfico Electrónico del Programa Buenos Aires de Historia Política, núm. 8, pp. 80-89. Disponible en: http://historiapolitica.com/ boletin8/. Fecha de acceso: 18 de noviembre de 2019.

Di Stefano, Roberto (2020). «La ciudad tomada. Ideología y espacialidad de un motín anticlerical (Buenos Aires, 1875)». En: Roberto Di Stefano (comp.). La ciudad secular. Religión y esfera pública urbana en la Argentina. Bernal: Universidad Nacional de Quilmes, Colección «Las ciudades y las ideas», pp. 22-51.

Di Stefano, Roberto y Loris Zanatta (2000). Historia de la Iglesia argentina. Desde la Conquista hasta fines del siglo XX. Buenos Aires: GrijalboMondadori.

Halperin Donghi, Tulio (1998). «Liberalismo argentino y liberalismo mexicano: dos destinos divergentes». En: Tulio Halperin Donghi. El 
espejo de la Historia. Problemas argentinos y perspectivas latinoamericanas. Buenos Aires: Sudamericana, pp. 141-165.

Rodríguez, Ana M. T. (2009). «Parroquias, misioneros ambulantes y feligreses en la Pampa Central (1896-1934)». En: Miranda Lida y Diego Mauro (comps.). Catolicismo y sociedad de masas en Argentina, 19001950. Rosario: Prohistoria.

Rodríguez, Ana M. T. (2014). «Las leyes laicas y la Iglesia Católica en los territorios del interior argentino (1884-1920)». Revista Brasileira De História Das Religiões, 7(19), pp. 71-90.

Rodríguez, Ana M. T. (2016). «Las batallas por la laicidad en los territorios del sur argentino. Una disputa en torno a los colegios religiosos en la primera década del siglo XX». Andes. Antropología e Historia, vol. 27, sin números de página.

Seiguer, Paula (2017) «Jamás he estado en casa». La Iglesia anglicana y los ingleses en la Argentina. Buenos Aires: Biblos.

Fecha de recepción: 19 de noviembre de 2020.

Fecha de evaluación: 6 de abril de 2021.

Fecha de aceptación: 7 de junio de 2021.

Fecha de publicación: 1 de noviembre de 2021.

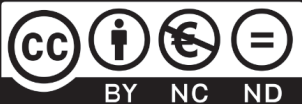

